\title{
Thermochemical parameters of 1,2,3,4-tetrahydroquinoline adducts of some divalent transition metal bromides
}

\section{Pedro Oliver Dunstan ${ }^{*}$}

Instituto de Química, Universidade Estadual de Campinas, Campinas, Brazil; *Corresponding Author: dunstan@iqm.unicamp.br

Received 14 May, 2011; revised 30 May 2011; accepted 4 June 2011.

\begin{abstract}
The adducts $\left[\mathrm{MBr}_{2}(\mathrm{~L})_{n}\right]$, where $\mathrm{M}=\mathrm{Fe}, \mathrm{Co}, \mathrm{Ni}, \mathrm{Cu}$ or $\mathrm{Zn} ; \mathrm{L}=1,2,3,4$-tetrahydroquinoline (THQ); $n=$ $0.75,1$ or 2 have been obtained from the interaction in hot solution of THQ with the metal(II) bromides. The compounds were characterized by melting points, elemental analysis, thermal analysis and IR spectroscopy. From calorimetric studies in solution, the standard enthalpies of formation of them and several other thermochemical parameters were determined. The mean standard enthalpies of the metal(II)-nitrogen bonds have been estimated.
\end{abstract}

Keywords: Transition Metal Complexes; Thermochemistry; Coordinated Bonds Energies; Dissolution Enthalpies; Calorimetry

\section{INTRODUCTION}

Quinoline and quinoline derivatives are known to form complexes with transition metal(II) halides [1-23]. Thermochemical parameters related to the transition metal(II)-nitrogen coordinated bonds formed in these compounds are not found in the literature. In a recent article [23] it was determined the values for several thermochemical parameters of adducts of some transition metal(II) bromides with quinoline. Following with the purpose of filling the lack of information on the energy evolved in the formation of these compounds, in the present article, it is reported the calorimetric determination of the energy involved in the formation of the coordinated metal(II)-nitrogen bonds, as well as, the values of several thermochemical parameters for the compounds formed between some metal(II) bromides with tetrahidroquinoline. The knowledge of these energy values is very important for understanding the coordinated metal(II)-nitrogen bonds formed. The thermodynamic properties of the compounds eventually could be used in determining their applications in catalysis and in the chromatographic separation of the metallic ions.

\section{EXPERIMENTAL}

1,2,3,4-Tetrahidroquinoline (98\%, Aldrich was purified by distillation through an efficient column and stored over Linde $4 \AA$ molecular sieves. All the anhydrous metal(II) bromides used in the preparation of the adducts were of reagent grade $(99 \%+)$. Solvents used in the synthesis of the compounds and in calorimetric measurements were purified by distillation and stored over Linde $4 \AA$ molecular sieves.

\subsection{Adducts Synthesis}

The adducts were prepared by the interaction of metal (II) bromides and ligand in solution. It was used hot ethanol or hot methanol. It was used a molar ratio salt/ligand of $1 / 4$ or $1 / 2$. Following, the solvent was evaporated by using vacuum. The solid obtain was re-crystallized, washed with three portions of petroleum ether and dried in vacuum. A typical procedure is given below.

\section{$\mathrm{CoBr}_{2}$-THQ}

To a solution of $1.0 \mathrm{~g}$ of $\mathrm{CoBr}_{2}(4.57 \mathrm{mmol})$ in $50 \mathrm{~mL}$ of hot ethanol, $2.3 \mathrm{~mL}(18.29 \mathrm{mmol})$ of tetrahidroquinoline was added slowly and dropwise under stirring. After filtering and evaporation of the solvent, a green solid was obtained. This was re-crystallized from chlorophorme. The product was dried for several hours in vacuum and stored in a desiccator over calcium chloride.

\subsection{Analytical and Physical Measurements}

Carbon, hydrogen and nitrogen were determined by micro analytical procedures [24]. Halide analysis was made by gravimetry using standard $\mathrm{N} / 10 \mathrm{AgNO}_{3}$ aqueous solution, after the adducts were dissolved in water 
[25]. Metal contents were determined by complexometric titration with $0.01 \mathrm{M}$ EDTA solution of aqueous solution of the adducts [26]. The capillary melting points of them were determined with a UNIMELT equipment from Thomas Hover. Spectra were obtained with samples in $\mathrm{KBr}$ matrix for the solid adducts. For tetrahidroquinoline, a film of the ligand sandwiched between $\mathrm{KBr}$ plates was used. A Perkin-Elmer 1600 series FT-IR spectrophotometer in the $4000-400 \mathrm{~cm}^{-1}$ region was used. TG/DTG and DSC measurements were obtained in argon atmosphere in a Du Pont 951 TG analyzer with the sample varying in mass from 5,58 to $19,94 \mathrm{mg}$ (TG/DTG) and from 2,44 to $9,09 \mathrm{mg}$ (DSC) and a heating rate of $10 \mathrm{~K} \cdot \mathrm{min}^{-1}$ in the $298-678 \mathrm{~K}(\mathrm{DSC})$ and 298-1248 (TG/DTG) temperature ranges. TG calibration for temperature was made with metallic aluminum as a standard $\left(\mathrm{mp}=660.37^{\circ} \mathrm{C}\right)$ and the equipment carried out the calibration for mass automatically. The DSC calibration was made with metallic indium as a standard $(\mathrm{mp}=$ $\left.165.73^{\circ} \mathrm{C}, \Delta_{\mathrm{s}}^{1} H^{\theta}=28.4 \mathrm{~J} \cdot \mathrm{g}^{-1}\right)$. Spectra in the $350-2000$ $\mathrm{nm}$ region were obtained with a UV-Vis-NIR VarianCary 5G spectrophotometer with a standard reflectance attachment for obtaining the spectra of the solid adducts. All the solution calorimetric measurements were carried out in an LKB 8700-1 calorimeter as described before [27]. The solution calorimetric measurements were performed by dissolving samples of $2.7-85.3 \mathrm{mg}$ of the adducts or metal(II) bromides in $100 \mathrm{~mL}$ of $1.2 \mathrm{M}$ aqueous $\mathrm{HCl}$ and the ligand in this last solution maintaining a molar relation salt/ligand equal to the stoichiometry of the adduct. The accuracy of the calorimeter was checked by determining the heat of dissolution of tris [(hydroxymethyl)amino] methane in $0.1 \mathrm{~mol} \cdot \mathrm{dm}^{-3} \mathrm{HCl}$. The result $\left(-29.78 \pm 0.03 \mathrm{~kJ} \cdot \mathrm{mol}^{-1}\right)$ is in agreement with the value recommended by IUPAC $(-29.763 \pm 0.003$ $\mathrm{kJ} \cdot \mathrm{mol}^{-1}$ ) [28].

\section{RESULTS AND DISCUSSION}

\subsection{Characterization of the Compounds}

All the adducts were solids. The yields range from $22 \%$ to $60 \%$. The capillary melting points and analytical data are summarized in Table 1.

\subsubsection{Infrared Studies}

The more important IR bands of the compounds are reported in Table 2. The spectra show shift of several bands after coordination with respect to the free ligand. Shifts to lower frequencies of the N-H stretching modes of the coordinated tetrahidroquinoline are observed. This is indicative of coordination to the metallic(II) ion through the nitrogen atom [13,29].

\subsubsection{Thermal Studies}

The themogravimetry of the compounds shows the

Table 1. Melting points, yields, appearance and analytical data of the adducts.

\begin{tabular}{cccccccc}
\hline \multirow{2}{*}{ Compound } & Yield \% & \multirow{2}{*}{$\mathrm{mp}^{\circ} \mathrm{C}$} & \multicolumn{5}{c}{$\%$ Calculated (found) } \\
\cline { 5 - 8 } & & & $\% \mathrm{C}$ & $\% \mathrm{H}$ & $\% \mathrm{~N}$ & $\% \mathrm{Br}$ & $\%$ Metal \\
\hline$\left[\mathrm{FeBr}_{2}(\mathrm{THQ})_{0.75}\right]$ & 34 & $108-11$ & $25.69(25.39)$ & $2.64(2.71)$ & $3.32(3.30)$ & $50.65(50.75)$ & $17.70(17.73)$ \\
{$\left[\mathrm{CoBr}_{2}(\mathrm{THQ})_{2}\right]$} & 32 & $235-38$ & $44.56(44.76)$ & $4.57(4.47)$ & $5.77(5.73)$ & $32.94(32.90)$ & $12.15(12.04)$ \\
{$\left[\mathrm{NiBr}_{2}(\mathrm{THQ})_{1.5}\right]$} & 89 & $368-71$ & $38.76(38.98)$ & $3.98(4.22)$ & $5.02(4.97)$ & $38.20(38.15)$ & $14.03(13.99)$ \\
{$\left[\mathrm{CuBr}_{2}(\mathrm{THQ})_{2}\right]$} & 5 & $95-98$ & $44.15(43.85)$ & $4.53(4.30)$ & $5.72(5.62)$ & $32.63(32.81)$ & $12.97(13.01)$ \\
{$\left[\mathrm{ZnBr}_{2}(\mathrm{THQ})_{2}\right]$} & 60 & $48-51$ & $51.91(51.80)$ & $5.32(5.23)$ & $6.73(6.55)$ & $25.58(25.69)$ & $10.46(10.50)$ \\
{$\left[\mathrm{ZnBr}_{2}(\mathrm{THQ})_{3}\right]$} & 22 & pastry & $43.98(43.70)$ & $4.51(4.33)$ & $5.70(5.57)$ & $32.51(32.56)$ & $13.30(13.34)$ \\
\hline
\end{tabular}

Table 2. Main IR spectral data $\left(\mathrm{cm}^{-1}\right)$ of the compounds.

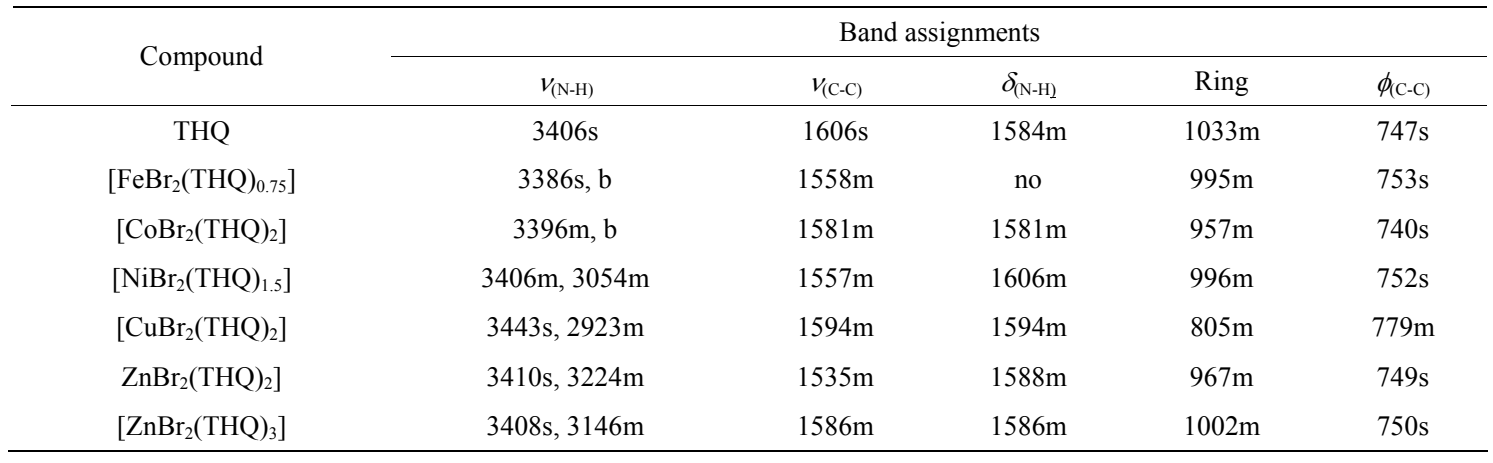


loss of part of the ligand in 2 - 4 steps of mass loss, alone or together with the loss of part of the bromine or with part of bromine and part of the metal content in the last step of mass loss. Bromine is lost in the last step or in the two final steps of mass loss, alone or together with the mass loss of part of the metal content. A residue is left that is part of the metal content. The DSC curves are consistent with the TG data. They present endothermic peaks due to the elimination of part of the ligand or part of bromine, alone or together with the elimination of part of the metal content. They present exothermic peaks due to the decomposition of the ligand or intermediate compounds. Table 3 presents the thermoanalytical data of the adducts.

\subsubsection{Electronic Spectra}

The ligand field parameters for the cobalt adduct have been calculated according to Lever [30]. Considering the number and position of the bands $[31,32]$ and according with the magnitude of the crystal field parameters as compared with that of Bolster [33], it is concluded that two nitrogen atoms from two ligand molecules and by two bromides ions pseudo-tetrahedrally surround $\mathrm{Co}$ (II) ion. The ligand field parameters for the Ni(II) adduct were calculated according to Reedijk et al. [34] and
Lever [30]. According to the number and position of the observed bands and considering the magnitude of the crystal field parameters as compared with that of Bolster [33], it is concluded that the Ni(II) ion is pseudo-tetrahedrally surrounded by two nitrogen atoms from two ligand molecules and two bromides ions, one of which is bridging to other $\mathrm{Ni}$ (II) ion in a dimeric structure. This last ion is surrounded by one nitrogen atom from one ligand molecule and three bromine ions, one of which is the mentioned bridge with the first nickel ion. For the $\mathrm{Cu}(\mathrm{II})$ adduct, the electronic spectra showed a rather broad asymmetrical band with maxima at $10528 \mathrm{~cm}^{-1}$. Its intensity and position correspond with those observe for pseudo-octahedral compounds [33], with the $\mathrm{Cu}$ (II) ion being surrounded by two nitrogen atoms from two ligand molecules and by four bromide ions in a bridge structure. The ligand parameters for the adduct of $\mathrm{Fe}(\mathrm{II})$ were calculated according to Bolster [33]. It is concluded that one unit is formed by $\mathrm{Fe}(\mathrm{II})$ ion pseudo-octahedrally surrounded by one nitrogen atom from one ligand molecule and five bromide ions in a polymeric structure bridging with other units of $\mathrm{Fe}(\mathrm{II})$ ion surrounded by six bromide ions. Table 4 contains the band maxima assignments and calculated ligand field parameters for the adducts.

Table 3. Thermal analysis of the compounds.

\begin{tabular}{|c|c|c|c|c|c|c|c|}
\hline \multirow{2}{*}{ Compound } & \multirow{2}{*}{$\begin{array}{c}\text { Apparent } \\
\text { mp K }\end{array}$} & \multicolumn{2}{|c|}{ Mass loss (\%) } & \multirow{2}{*}{$\begin{array}{l}\text { TG temperature } \\
\text { range } K\end{array}$} & \multirow{2}{*}{ Species lost } & \multirow{2}{*}{$\begin{array}{c}\text { DSC peak } \\
\text { temperature }\end{array}$} & \multirow{2}{*}{$\Delta H^{\theta}\left(\mathrm{kJ} \cdot \mathrm{mol}^{-1}\right)$} \\
\hline & & Calcd. & Obs. & & & & \\
\hline \multirow[t]{5}{*}[\mathrm{FeBr}_{2}(\mathrm{THQ})_{0.75}]{} & $381-4$ & 7.60 & 7.70 & $356-394$ & $-0.18 \mathrm{~L}$ & 394 & 61.63 \\
\hline & & 24.05 & 24.82 & $394-562$ & $-0.57 \mathrm{~L}$ & 507 & 1.59 \\
\hline & & 17.73 & 17.71 & $914-938$ & $-0.70 \mathrm{Br}$ & & \\
\hline & & 25.33 & 25.73 & $938-1086$ & $-\mathrm{Br}$ & & \\
\hline & & & 24.04 & 1248 & residue & & \\
\hline \multirow{3}{*}[\mathrm{CoBr}_{2}(\mathrm{THQ})_{2}]{} & & 27.45 & 23.47 & $546-565$ & $-\mathrm{L}$ & 516 & 27.44 \\
\hline & & 34.13 & 38.68 & $565-957$ & $-2 \mathrm{Br}-0.1 \mathrm{Co}$ & 530 & 6.48 \\
\hline & & & 10.63 & 1248 & residue & & \\
\hline \multirow[t]{3}{*}[\mathrm{NiBr}_{2}(\mathrm{THQ})_{1.5}]{} & $368-71$ & 16.72 & 16.39 & $369-409$ & $-0.7 \mathrm{~L}$ & 387 & 71.16 \\
\hline & & 36.79 & 37.24 & $409-494$ & $-1.3 \mathrm{~L}-0.3 \mathrm{Br}$ & 441 & -75.95 \\
\hline & & 32.47 & 32.64 & $846-959$ & $-1.7 \mathrm{Br}$ & 490 & 90.66 \\
\hline \multirow[t]{5}{*}[\mathrm{CuBr}_{2}(\mathrm{THQ})_{2}]{} & $428-31$ & 6.80 & 6.40 & $365-399$ & $-0.25 \mathrm{~L}$ & 372 & -19.40 \\
\hline & & 14.96 & 15.09 & $399-508$ & $-0.55 \mathrm{~L}$ & 399 & -1.22 \\
\hline & & 8.16 & 8.47 & $508-646$ & $-0.30 \mathrm{~L}$ & 439 & -28.63 \\
\hline & & 61.00 & 60.80 & $646-1056$ & $-0.90 \mathrm{~L}-2 \mathrm{Br}-0.3 \mathrm{Cu}$ & 499 & 1.59 \\
\hline & & & 9.24 & 1248 & residue & & \\
\hline \multirow[t]{4}{*}[\mathrm{ZnBr}_{2}(\mathrm{THQ})_{2}]{} & $321-4$ & 35.22 & 35.48 & $228-544$ & $-1.3 \mathrm{~L}$ & 357 & 31.15 \\
\hline & & 54.13 & 54.31 & $544-742$ & $-0.7 \mathrm{~L}-2 \mathrm{Br}-0.2 \mathrm{Zn}$ & 284 & -5.08 \\
\hline & & 8.65 & 8.28 & $742-1069$ & $-0.65 \mathrm{Zn}$ & 496 & -3.24 \\
\hline & & & 1.93 & 1248 & residue & & \\
\hline \multirow[t]{5}{*}{$\mathrm{ZnBr}_{2}(\mathrm{THQ})_{3}$} & pastry & 42.64 & 44.20 & $392-526$ & $-2 \mathrm{~L}$ & 320 & 27.22 \\
\hline & & 34.11 & 36.16 & $526-732$ & $-\mathrm{L}-\mathrm{Br}$ & 448 & -28.86 \\
\hline & & 12.79 & 10.25 & $813-831$ & $-\mathrm{Br}$ & & \\
\hline & & 6.28 & 5.11 & $831-/ 1020$ & $-0.60 Z n$ & & \\
\hline & & & 4.28 & 1248 & residue & & \\
\hline
\end{tabular}


Table 4. Band maxima and calculated ligand field parameters for the compounds.

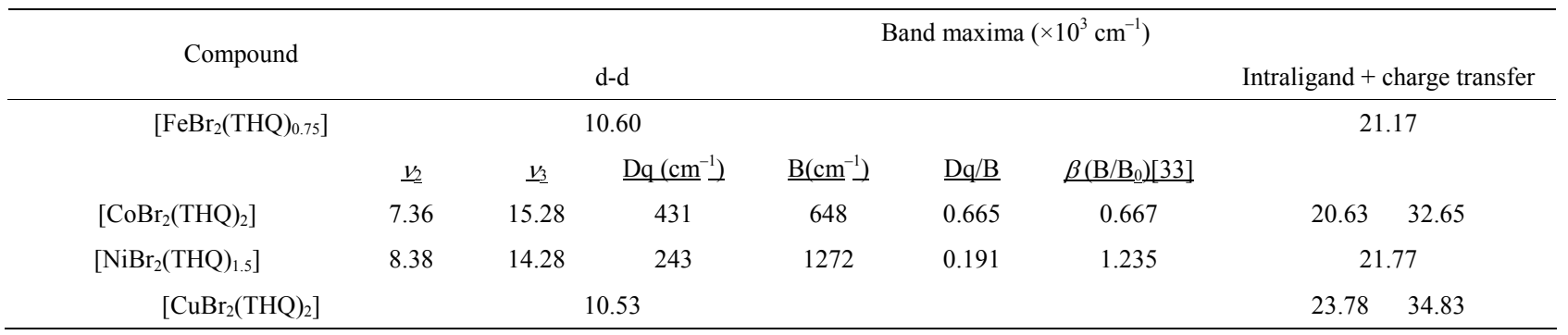

\subsubsection{Calorimetric Measurements}

The standard enthalpies of dissolution of metal(II) bromides, tetrahidroquinoline and adducts were obtained as previously reported [27]. The standard enthalpies of dissolution were obtained according to the standard enthalpies of the following reactions in solution:

$$
\begin{array}{r}
\mathrm{MBr}_{2(\mathrm{~s})}+\text { calorimetric solvent } \rightarrow \text { solution } \mathrm{A}, \Delta_{1} H^{\theta} \\
\mathrm{n} \mathrm{THQ}_{(1)}+\text { solution } \mathrm{A} \rightarrow \text { solution } \mathrm{B}, \Delta_{2} H^{\theta} \\
{\left[\mathrm{MBr}_{2}(\mathrm{THQ}) \mathrm{n}\right]_{(\mathrm{s})}+\text { calorimetric solvent } \rightarrow} \\
\text { solution } \mathrm{C}, \Delta_{3} H^{\theta} \\
\text { solution } B \rightarrow \text { solution } \mathrm{C}, \Delta_{4} H^{\theta}
\end{array}
$$

The application of Hess' law to the series of reactions (1) - (4) gives the standard enthalpies of the acid/base reactions $\left(\Delta_{\mathrm{r}} H^{\theta}\right)$ according to the reaction:

$$
\mathrm{MBr}_{2(\mathrm{~s})}+\mathrm{n} \mathrm{THQ}_{(1)} \rightarrow\left[\mathrm{MBr}_{2}(\mathrm{THQ})_{\mathrm{n}}\right]_{(\mathrm{s})}, \Delta_{\mathrm{r}} H^{\theta}
$$

where $\Delta_{\mathrm{r}} H^{\theta}=\Delta_{1} H^{\theta}+\Delta_{2} H^{\theta}-\Delta_{3} H^{\theta}$ since the final thermodynamic state of reactions (2) and (3) is the same and $\Delta_{4} H^{\theta}=0$. Table 5 gives the values obtained for the enthalpies of dissolution of $\mathrm{MBr}_{2}\left(\Delta_{1} H^{\theta}\right)$, THQ into the solution of $\operatorname{MBr}_{2}\left(\Delta_{2} H^{\theta}\right)$ and of the adducts $\left(\Delta_{3} H^{\theta}\right)$. Uncertainty intervals given in this table are twice the standard deviation of the mean of 4 - 9 replicate measurements. The thermochemical parameters were calculated for hypothetical monomeric adducts. From the values obtained for the standard enthalpies of the acid/base reactions $\left(\Delta_{\mathrm{r}} H^{\theta}\right)$ and by using appropriate thermochemical cycles [29], the following thermochemical parameters for the adducts were determined: the standard enthalpies of formation $\left(\Delta_{\mathrm{f}} H^{\theta}\right)$, the standard enthalpies of decomposition $\left(\Delta_{\mathrm{D}} H^{\Theta}\right)$, the standard lattice enthalpies $\left(\Delta_{\mathrm{M}} H^{\Theta}\right)$ and the standard enthalpies of the Lewis acid/base reactions in the gaseous phase $\left(\Delta_{\mathrm{r}} H^{\theta}(\mathrm{g})\right)$. These later values can be used to calculate the standard enthalpies of the M-N bonds, being equal to $\bar{D}_{(\mathrm{M}-\mathrm{N})}=-\Delta_{\mathrm{r}} H^{\theta}(\mathrm{g}) / \mathrm{n}[35]$. Table 6 lists the values of all these thermochemical parameters. The standard enthalpies of: formation and

Table 5. Enthalpies of dissolution at $298.15 \mathrm{~K}$.

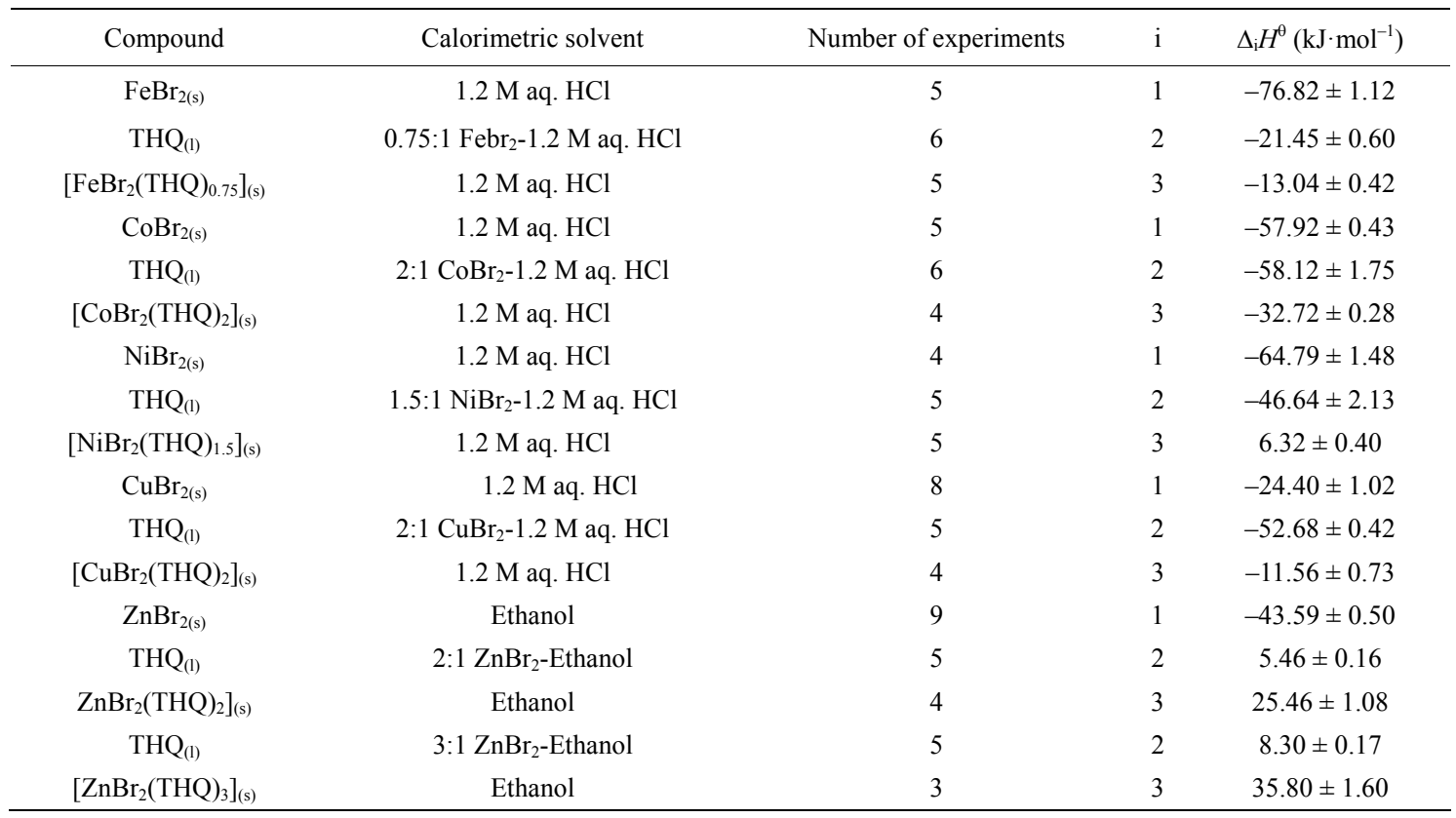


Table 6. Summary of the thermochemical results $\left(\mathrm{KJ} \cdot \mathrm{mol}^{-1}\right)$ for the compounds.

\begin{tabular}{|c|c|c|c|c|c|c|c|}
\hline Compound & $\Delta_{\mathrm{r}} H^{\theta}$ & $\Delta_{\mathrm{f}} H^{\theta}$ & $\Delta_{\mathrm{s}, \mathrm{l}}^{\mathrm{g}} H^{\theta}$ & $\Delta_{\mathrm{M}} H^{\theta}$ & & & \\
\hline $\mathrm{FeBr}_{2(\mathrm{~s})}$ & & $-249.8[36]$ & 204 [37] & & & & \\
\hline $\mathrm{CoBr}_{2(\mathrm{~s})}$ & & $-220.9[36]$ & $183[37]$ & & & & \\
\hline $\mathrm{NiBr}_{2(\mathrm{~s})}$ & & $-212.1[36]$ & $170[37]$ & & & & \\
\hline $\mathrm{CuBr}_{2(\mathrm{~s})}$ & & $-141.8[36]$ & $182.4[37]$ & & & & \\
\hline $\mathrm{ZnBr}_{2(\mathrm{~s})}$ & & $-328.65[36]$ & $159.7[37]$ & & & & \\
\hline $\mathrm{THQ}_{(\mathrm{l})}$ & & 38.15 & 59.22 & & & & \\
\hline$\left[\mathrm{FeBr}_{2}(\mathrm{THQ})_{0.75}\right]_{(\mathrm{s})}$ & $-85.27 \pm 1.34$ & $-306.5 \pm 2.5$ & $132 \pm 16[38]$ & $-318 \pm 2$ & $113.88 \pm 2.41$ & $-186 \pm 16$ & $248 \pm 21$ \\
\hline$\left[\mathrm{CoBr}_{2}(\mathrm{THQ})_{2}\right]_{(\mathrm{s})}$ & $-83.32 \pm 1.82$ & $-227.9 \pm 2.9$ & $121 \pm 15[38]$ & $-385 \pm 3$ & $201.76 \pm 2.70$ & $-264 \pm 15$ & $132 \pm 8$ \\
\hline$\left[\mathrm{NiBr}_{2}(\mathrm{THQ})_{1.5}\right]_{(\mathrm{s})}$ & $-105.11 \pm 2.62$ & $-260.0 \pm 3.2$ & $115 \pm 14[38]$ & $-331 \pm 3$ & $162.34 \pm 3.02$ & $-217 \pm 14$ & $145 \pm 9$ \\
\hline$\left[\mathrm{CuBr}_{2}(\mathrm{THQ})_{2}\right]_{(\mathrm{s})}$ & $-65.52 \pm 1.32$ & $-131.0 \pm 3.1$ & $120.8 \pm 14.5[38]$ & $-324.2 \pm 2.6$ & $-141.82 \pm 2.40$ & $-203.4 \pm 14.7$ & $101.7 \pm 7.4$ \\
\hline$\left[\mathrm{ZnBr}_{2}(\mathrm{THQ})_{2}\right]_{(\mathrm{s})}$ & $-63.59 \pm 1.20$ & $-315.94 \pm 3.07$ & $109.5 \pm 13.1[38]$ & $-341.7 \pm 3.1$ & $182.03 \pm 2.33$ & $-232.2 \pm 13.5$ & $116.1 \pm 6.8$ \\
\hline$\left[\mathrm{ZnBr}_{2}(\mathrm{THQ})_{3}\right]_{(\mathrm{s})}$ & $-71.09 \pm 1.68$ & $-285.29 \pm 3.98$ & $109.5 \pm 13.1[38]$ & $-408.5 \pm 4.0$ & $248.75 \pm 3.43$ & $-299.0 \pm 13.7$ & $99.7 \pm 4.6$ \\
\hline
\end{tabular}

Table 7. Auxiliary data and enthalpy changes of the ionic complex formation process in the gaseous phase $\left(\mathrm{KJ} \cdot \mathrm{mol}^{-1}\right)$.

\begin{tabular}{|c|c|c|c|}
\hline Compound & $\Delta_{\mathrm{f}} H^{\theta}$ & $\Delta_{\mathrm{fl}} H^{\theta}$ & \\
\hline $\mathrm{Br}_{(\mathrm{g})}^{-}$ & $-219.07[36]$ & & \\
\hline $\mathrm{Fe}^{2+}{ }_{(\mathrm{g})}$ & $2751.6 \pm 2.3[39]$ & & \\
\hline $\mathrm{Co}^{2+}{ }_{(\mathrm{g})}$ & $2841.7 \pm 3.4[39$ & & \\
\hline $\mathrm{Ni}^{2+}(\mathrm{g})$ & $2930.5 \pm 1.5[39]$ & & \\
\hline $\mathrm{Cu}^{2+}{ }_{(\mathrm{g})}$ & $3054.5 \pm 2.1[39]$ & & \\
\hline $\mathrm{Zn}^{2+}{ }_{(\mathrm{g})}$ & $2781.0 \pm 0.4[39]$ & & \\
\hline$\left[\mathrm{FeBr}_{2}(\mathrm{THQ})_{0.75}\right]_{(\mathrm{g})}$ & $-362 \pm 16$ & $-186 \pm 16$ & $-2748 \pm 16$ \\
\hline$\left[\mathrm{CoBr}_{2}(\mathrm{THQ})_{2}\right]_{(\mathrm{g})}$ & $-107 \pm 15$ & $-264 \pm 15$ & $-2705 \pm 16$ \\
\hline$\left[\mathrm{NiBr}_{2}(\mathrm{THQ})_{1.5}\right]_{(\mathrm{g})}$ & $-113 \pm 14$ & $-217 \pm 14$ & $-2751 \pm 14$ \\
\hline$\left[\mathrm{CuBr}_{2}(\mathrm{THQ})_{2}\right]_{(\mathrm{g})}$ & $31.9 \pm 15.0$ & $203.4 \pm 14.7$ & $-2778.9 \pm 15.4$ \\
\hline$\left[\mathrm{ZnBr}_{2}(\mathrm{THQ})_{2}\right]_{(\mathrm{g})}$ & $-206.5 \pm 13.7$ & $-232.2 \pm 13.5$ & $-2741.1 \pm 13.9$ \\
\hline$\left[\mathrm{ZnBr}_{2}(\mathrm{THQ})_{3}\right]_{(\mathrm{g})}$ & $-175.9 \pm 14.1$ & $-299.0 \pm 13.7$ & $-2810.9 \pm 14.6$ \\
\hline
\end{tabular}

sublimation of THQ as these values are not found in the literature. They were calculated by a group contribution method, from the enthalpies values for quinoline [40-42]. The enthalpies for the process of hypothetical monomer complex formation in the gaseous phase, from metal(II) ions, bromide ions and THQ molecules can be evaluated:

where

$$
\begin{aligned}
& \mathrm{M}_{(g)}{ }^{2+}+2 \mathrm{Br}(g)^{-}+\mathrm{n} \mathrm{THQ}_{(g)} \rightarrow \\
& {[\mathrm{MBr} 2(\mathrm{THQ}) \mathrm{n}](\mathrm{g}), \Delta_{\mathrm{fJ}} H^{\theta}}
\end{aligned}
$$

$$
\Delta_{\mathrm{fI}} H^{\theta}=\Delta_{\mathrm{f}} H^{\theta}\left(\operatorname{adduct}_{(\mathrm{g})}\right)-\Delta_{\mathrm{f}} \mathrm{H}^{\theta}\left(\mathrm{M}_{(\mathrm{g})}{ }^{2+}\right)
$$

$$
-2 \Delta_{\mathrm{f}} \mathrm{H}^{\theta}\left(\mathrm{Br}_{(\mathrm{g})}{ }^{-}\right)-\mathrm{n} \Delta_{\mathrm{f}} \mathrm{H}^{\theta}\left(\mathrm{THQ}_{(\mathrm{g})}\right)
$$

Table 7 lists the values obtained for these enthalpies values.

\section{CONCLUSIONS}

The interaction of transition metal(II) bromides with tetrahidroquinoline produced solid adducts of defined stoichiometry. The calorimetric study of them determined the standard enthalpies of formation and several other thermochemical parameters. The mean standard enthalpies of metal(II)-nitrogen coordinate bonds have values from 100 to $248 \mathrm{KJ} \cdot \mathrm{mol}^{-1}$. Comparing with the values obtained for quinoline adducts of metal(II) bromides of the same stoichiomety [23], it is observed that the bonds formed by THQ are weaker than the bonds 
formed by quinoline. This means that the hydrogenation of the heterocycle of quinoline to get THQ leads to the weakness of the bond formed by the nitrogen atom with metal(II) ions. The basicity order of the ligands is: THQ $<$ quinoline. Based on the $\Delta_{\mathrm{r}} H^{\theta}$ values obtained for the adducts, the acidity order of the salts, for the adducts of the same stoichiometry can be established: $\mathrm{CoBr}_{2}>$ $\mathrm{CuBr}_{2}>\mathrm{ZnBr}_{2}$. Using the $\bar{D}_{(\mathrm{M}-\mathrm{N})}$ values, the order is: $\mathrm{CoBr}_{2}>\mathrm{ZnBr}_{2}>\mathrm{CuBr}_{2}$.

\section{REFERENCES}

[1] Goodgame, M. (1963) Octahedral, tetrahedral, and planar complexes of nickel(II) with quinoline. Journal of the Chemical Society, 207-211. doi:10.1039/jr9630000207

[2] Brown, D.H., Nuttall, R.N. and Sharp, D.W.A. (1964) Thermal decomposition of metal complexes. II. The decomposition of some bisquinoline metal(II) halides. Journal of Inorganic and Nuclear Chemistry, 26, 11511156. doi:10.1016/0022-1902(64)80192-5

[3] Goodgame, D.M.L., Goodgame, M. and Weeks, M.J. (1964) Spectral and magnetic studies of some polymeric complexes of nickel halides with heterocyclic ligands. Journal of the Chemical Society, 5194-5199. doi:10.1039/jr9640005194

[4] Majumdar, A.K., Mukherjee, A.K. and Mukherjee, A.K. (1964) Thermal decomposition of nitrogen ligated nickel(II) complexes and isolation of new compounds. Journal of Inorganic and Nuclear Chemistry, 26, 2177-2184. doi:10.1016/0022-1902(64)80163-9

[5] Allan, J.R., Brown, D.H., Nuttall, R.H. and Sharp, D.W.A. (1965) The far infrared spectra of some transition metal halide complexes with substituted pyridines. Journal of Inorganic and Nuclear Chemistry, 27, 1305-1309. doi:10.1016/0022-1902(65)80094-X

[6] Goodgame D.M.L. and Goodgame, M. (1965) Near-infrared spectra of some pseudotetrahedral complexes of cobalt(II) and nickel(II). Inorganic Chemistry, 4, 139-143. doi:10.1021/ic50024a002

[7] Forster, D. and Goodgame, D.M.L. (1965) Preparation and electronic spectra of some tetrahedral complexes of iron(II). Journal of the Chemical Society, 454-458. doi:10.1039/jr9650000454

[8] Lever, A.B.P. (1965) The magnetic moments of some tetragonal nickel complexes. Inorganic Chemistry, 4, 763-764. doi:10.1021/ic50027a041

[9] Clark, R.J.H. and Williams, C.S. (1966) Infrared spectra (200-3000 $\left.\mathrm{cm}^{-1}\right)$ of metal-isothiocynate complexes. Spectrochimica Acta, 22, 1081-1090. doi:10.1016/0371-1951(66)80198-4

[10] Brown, D.H., Nuttall, R.H., Mcavoy, J. and Sharp, D.W.A. (1966) Pyridine, $\gamma$-picoline, and quinoline complexes of transition metal perchlorates and tetrafluoroborates. Journal of the Chemical Society (A), 892-896.

[11] Dowing, R.D. Gibson, J.F., Goodgame, D.M.L., Goodgame M. and Hayward, P.J. (1969) Electron and spin resonance spectra of some distorted tetrahedral manganese(II) complexes. Journal of the Chemical Society $(A)$,
$1242-1248$

[12] Haigh, J.M., Hancock, R.D., Hulett, L.G. and Thorton, D.A. (1969) Crystal field aspects of vibrational spectra. II. First-row transition metal(II) complexes with nitrogen donors. Journal of Molecular Structure, 4, 369-375. doi:10.1016/0022-2860(69)85004-0

[13] Mohapatra, B.K. and Romana Rao, D.V. (1970) Mixed ligand complexes of zinc benzoyl-acetonate with substitute pyridines and quinolines. Inorganic Chimica Acta, $\mathbf{4}$, 404-406. doi:10.1016/S0020-1693(00)93314-0

[14] Garaibba, E., Micera, G., Sanna, D. and Lodyga-Chruscinska, E. (2003) Oxano-Vanadium(IV) complexes of quinoline derivatives. Inorganic Chimica Acta, 348, 97106. doi:10.1016/S0020-1693(02)01483-4

[15] Parihari, R.K., Patel, R.K. and Patel, R.N. (2000) Synthetic and structural studies of the transition metal complexes of manganese-, cobalt- and zinc(II) with m-nitrobenzal-dehyde thiosemicarbazone and some neutral ligands. Indian Chemical Society, 77, 289-290.

[16] Niven, M.L. and Thornton, D. (1979) The infrared spectra of quinoline complexes of metal(II) halides and isothiocynates: assignments by isotopic labeling and structural aspects of the spectra. Journal of Molecular Structure, 52, 157-163. doi:10.1016/0022-2860(79)80338-5

[17] Yurdakal, S., Akyoz, S. and Davies, J.E.D. (1988) An infrared and Raman spectroscopic study of transition metal(II) halide quinoline complexes. Journal of Molecular Structure, 174, 435-441. doi:10.1016/0022-2860(88)80197-2

[18] Abdel-Rahman, M., Gaber, S.D. and Hafez, A.K. (1985) Studies of some quinoline derivatives II. Acta Chimica Hungarica, 120, 251-260.

[19] Garg, B.S., Garg, R.K. and Reddy, M.J. (1993) Synthesis and spectral characterization of zinc(II), cadmium(II) and mercury(II) with tetrahidroquinoline and tetrahidroquinoline dithiocarbamates. Indian Journal of Chemistry, 32A, 697-700.

[20] Sharma, N. (2010) Synthesis, phisicochemical and antimicrobial studies of first row transition metal complexes with quinoline derivatives nitroquinolino [3,2-b] $[1,5]$ benzodiazephine and nitroquinolino [3,2-b] [1,5] benzooxazepine. The electronic Journal of Chemistry, 2, 277-287.

[21] Kulkami, N.V., Hegde, G.S., Kurdekar, G.S., Budagumpi, S., Sathisha, M.P., and Revankar, V.K. (2010) Spectroscopy, electrochemistry, and structure of 3d-transition metal complexes of thiosemicarbazones with quinoline core: Evaluation of antimicrobial propery. Spectroscopy Letters, 43, 235-246. doi:10.1080/00387010903329383

[22] Marlier, E.E., Sadowsky, D., Cramer, C.J., McNeill, K. (2010) Metal ion size and coordination mode in complexes of $\beta$-diketiminate ligand with pendant quinoline arms. Inorganica Chimica Acta, 391, 173-179.

[23] Dunstan, P.O. (2008) Thermochemistry of adducts of some bivalent transition metal bromides with quinoline. Thermochimica Acta, 468 21-26. doi:10.1016/j.tca.2007.11.018

[24] Niederl, J.B. and Sozzi, J.A. (1958) Microanálises elemental orgánico. Methopress, Buenos Aires.

[25] Kolthoff, I.M. and Sandall, E.B. (1956) Tratado de química analítica cuantitativa. 3rd Edition, Librería y 
Editorial Nigar S. R. L., Buenos Aires.

[26] Flashka, H.A. (1964) Edta titrations: An introduction to theory and practice. 2th Edition, Pergamon Press, London.

[27] Dunstan, P.O. (2005) Thermochemical parameters of $\alpha$-picoline $\mathrm{N}$-oxide adducts of some divalent transition metal bromides. Journal of Thermal Analisis and Calorimetry, 79, 355-359. doi:10.1007/s10973-005-0064-4

[28] Henrington, E.F. (1974) Recommendation reference materials for the realization of physicochemical properties (recommendation approved 1974). Pure and Applied Chemistry, 40, 391-450. doi:10.1351/pac197440030391

[29] Dunstan, P.O. (2010) Thermochemistry of quinoline and morpholine aducts of cadmium(II) halides. Journal of Chemical and Engineering Data, 55, 4995-4998. doi:10.1021/ed045p711

[30] Lever, A.B.P. (1968) Electronic spectra of some transition metal complexes. Derivation of D (sub q) and B. Journal of Chemical Education, 45, 711-712. doi:10.1021/ed045p711

[31] West, D.X. and Severns, J.C. (1988) Cobalt(II) complexes of the 2-aminopicoline N-oxide and 2-amino-4, 6-lutidine N-oxide. Transition Metal Chemistry, 13, 4549. doi:10.1007/BF01041498

[32] Brown, D.H., Kenyon, D. and Sharp, D.W.A. (1969) Thermal decomposition of some pyridine N-oxide and substituted pyridine N-oxide complexes of manganese(II), cobalt(II), nickel(II), and zinc(II) halides. Journal of the Chemical Society $(A), 1474-1477$.

[33] Bolster, M.W.G. (1972) The coordination chemistry of aminophosphinoxide and related compounds. Thesis, Leiden University, Leiden.

[34] Reedijk, J., Van Lecuwen, P.W.N.M. and Groenveld, W.L. (1968) Semi-empirical energy-level diagram for octahedral nickel(II) complexes. Recueil des Travaux Chimiques des Pays-Bas, 87, 129-143. doi:10.1002/recl.19680870203

[35] Dunstan, P.O. and dos Santos, L.C.R. (1989) Thermo- chemistry of amide and thioamide complexes of arsenic trihalides. Thermochimica Acta, 156, 163-177. doi:10.1016/0040-6031(89)87182-5

[36] Wagmam, D.D., Evans, W.H. Parker, V.B., Schumn, R.H., Hallow, I., Churney, S. and Nuttall, R.L. (1982) The NBS table of chemical thermodynamic properties. Selected values for inorganic and $\mathrm{C}_{1}$ and $\mathrm{C}_{2}$ organic substances in SI units. Journal of Physical and Chemical Reference Data, 2, 50, 139, 155, 166, 171, 178.

[37] Dunstan, P.O. (2004) Thermochemistry of adducts of some transition metal(II) bromides with pyridine $\mathrm{N}$-oxide. Thermochimica Acta, 409, 19-24. doi:10.1016/S0040-6031(03)00333-2

[38] Davydova, E.I., Savastionova, J.N., Suvorov, A.V. and Timoshkin, A.Y. (2010) Molecular complexes formed by halides of group 4, 5, 13-14 elements and thermodynamic characterization of their vaporization and dissociation found by static tensimetric method. Coordination Chemistry Reviews, 254, 2031-2077. doi:10.1016/i.ccr.2010.04.001

[39] Skinner, H.A. and Pilcher, G. (1963) Bond-energy-term values in hydrocarbons and related compounds. Quarterly Reviews (London), 17, 264-288.

[40] Cox, J.D. and Pilcher, G. (1970) Thermochemistry of organic and organo-metallic compounds. 2th Edition, Academic Press, London.

[41] Ducros, M., Cruson, J.F. and Sannier, H. (1980) Estimation des enthalpies de vaporization des composes organiques liquedes parte 1. Applications aux alcanes, cyclo-alcanes, alcenes, hydrocarbures benzeniques, alcool, alcanes thiols et aldehys. Thermo-chimica Acta, 36, 39-65. doi:10.1016/0040-6031(80)80109-2

[42] Ducros, M., Cruson, J.F.and Sannier, H. (1981) Estimation dês enthalpies de vaporisa-tion des composes organiques liquides parte 2. Applicatins aux ethersoxydes, thioalcanes, cetones et amines. Thermochimica Acta, 44, 131-140. doi:10.1016/0040-6031(81)80035-4 